\title{
IMAGINARIO INFANTIL EN EL MUNDO ANDINO
}

Rodolfo Sánchez Garrafa ${ }^{1}$

\section{RESUMEN}

El artículo expone una aproximación antropológica al imaginario infantil andino. A partir de una visión general sobre el desarrollo gradual de la inteligencia y de la capacidad de pensar en los siete primeros años de la niñez, examina las posiciones educativas actuales que considera más relevantes respecto al imaginario infantil, para pasar luego a proporcionar información sobre las interacciones de los niños en comunidades andinas y, consiguientemente, sobre los procesos de socialización y enculturación que éstos experimentan a lo largo de su desarrollo.

PALABRAS CLAVE: mundo andino, imaginario infantil, socialización primaria, oralidad, enculturación.

\author{
ABSTRACT \\ The present article exposes an anthropological \\ approach to the imagination of the Andean children. \\ From an overview of the gradual development of \\ intelligence and thinking capacity in the first seven \\ years of childhood, he examines the current \\ educational positions most relevant to the child's \\ imagination and then provides information on the \\ children's interactions in the Andean communities and \\ consequently on the processes of socialization and \\ inculturation that they experiences throughout their \\ development. \\ KEYWORDS: andean world, children's imaginary, \\ primary socialization, orality, enculturation.
}

1 Investigador Social, antropólogo por la Universidad Nacional de San Antonio Abad del Cusco, magíster en antropología por la Pontificia Universidad Católica del Perú, doctor en ciencias sociales por la Universidad Nacional Mayor de San Marcos. E-mail: rodosang@hotmail.com 
E mpezamos preguntándonos: ¿Por qué interesarnos por el imaginario infantil? La respuesta, que no es tan obvia como podría suponerse, nos pone frente a un escenario de veras sugerente.

La educación inicial se orienta a la formación integral del niño. Busca desarrollar su inteligencia, emociones, afectos, sensibilidad, dinamismo, lenguaje, en suma asegurar el desarrollo de todas las potencialidades del niño y la afirmación de su personalidad. Con este propósito, los educadores se preocupan por ofrecerle al niño oportunidades para

"La manera cómo el niño logra un conocimiento de sí mismo y llega a elaborar una interpretación del mundo, tiene que ver con el desarrollo de sus estructuras intelectuales y la evolución de su capacidad de representarse los objetos y seres de su entorno."

descubrirse a sí mismo y descubrir el mundo, para interactuar con los objetos y con otros niños, y para expresarse libre y creativamente. La antropología concurre, a este efecto, proporcionando información sobre las interacciones del niño y los procesos de socialización y enculturación que éste experimenta a lo largo de su desarrollo.

La manera cómo el niño logra un conocimiento de sí mismo y llega a elaborar una interpretación del mundo, tiene que ver con el desarrollo de sus estructuras intelectuales y la consiguiente evolución de su capacidad de representarse los objetos y seres de su entorno. En cierta etapa de su desarrollo intelectual, el niño llega a ser capaz de imaginar los actos que desea realizar y puede pensar sobre los que ya ha efectuado, pero no se molesta en demostrar lo que está diciendo. Hasta los siete años el niño asimila a su propio punto de vista lo que escucha, sus representaciones están ligadas a sus percepciones y asimila las relaciones causales (causa-efecto) y lógicas (razón-consecuente) a las relaciones psicológicas (motivo-acción). Es por esto que para entender el carácter del imaginario infantil hay que tener presente el desarrollo gradual de su capacidad de pensar.

\section{ABORDAJE TEÓRICO}

\section{El desarrollo intelectual}

Las estructuras intelectuales del ser humano se forman, modifican y transforman a lo largo de un proceso de desarrollo evolutivo y de interacción con el ambiente, que según Piaget (1985, 1973), configura cuatro etapas con características propias y diferenciadas: sensoriomotriz, pre-operacional, de las operaciones concretas, y de las operaciones formales. De estas etapas, nos interesan particularmente las dos primeras, porque cubren los siete primeros años de la niñez, lapso vital con el que de diversos modos se halla comprometida la educación inicial.

Etapa de la inteligencia sensoriomotriz

Durante los dos primeros años de vida del ser humano, las conductas inteligentes se forman a partir de patrones hereditarios a los que comúnmente conocemos como reflejos o conducta instintiva.

En esta etapa, el infante comienza a organizar sus imágenes visuales y controlar sus respuestas motoras, coordinando sus diferentes experiencias 
sensoriales con referencia a una fuente de estimulación (gradualmente aprende a mirar a quien habla, a agarrar lo que ve, etc.). De este modo, el infante consigue efectuar sus primeros ajustes o adaptaciones frente a la estimulación proveniente del entorno inmediato.

A través de una relación constante con el medio ambiente, adquiere la capacidad de considerar la permanencia del objeto. En sus primeros meses de vida, el niño que deja caer un objeto de la mano, considera que éste desapareció; unos meses después, el niño ya intenta encontrar el objeto que salió fuera de su campo visual. Por medio de la exploración y coordinación el niño realiza una asimilación-adaptación sensoriomotriz de la realidad.

Cuando culmina esta etapa, el niño ya se muestra capaz de seguir una secuencia de acciones para conseguir una meta o usar un instrumento para alcanzar un objeto, e incluso encontrarlo si éste desaparece. No obstante, el pensamiento del niño todavía está limitado a las experiencias sensoriales inmediatas y a las acciones motrices.

Etapa de la inteligencia pre-operacional

Entre los dos y siete años emerge el lenguaje, y su adquisición favorece el tránsito del plano sensoriomotriz al plano del pensamiento concreto. En esta etapa, la percepción y la motricidad se siguen ejerciendo sin cargarse de significaciones nuevas ni integrarse en nuevos sistemas de comprensión, pero el niño tiende a reconstruir el todo sobre un plano nuevo. Por consiguiente, el pensamiento no es una traducción ni una simple continuación de lo sensomotor en lo representativo.

Entre las condiciones esenciales para pasar del plano sensoriomotor al plano reflexivo se considera: La mayor rapidez en las acciones que el niño coordina; la conciencia que el niño toma de los pasos que sigue para alcanzar una meta y comprobar el éxito; y, el incremento de las distancias, de modo que las experiencias sobre la realidad se prolongan mediante acciones simbólicas.

Se distingue dos sub-etapas o estadios: pensamiento simbólico y pensamiento intuitivo.

\section{Pensamiento simbólico o pre-conceptual}

En este estadio empiezan a manifestarse nuevas aptitudes del niño, directamente relacionadas con la representación de los objetos: adquisición gradual del lenguaje, aparición del juego simbólico y los primeros intentos de representación gráfica.

Mediante la función simbólica el niño adquiere la capacidad de representar lo real a través de los llamados "significantes", que son diferentes de las cosas "significadas". Sin embargo, el desarrollo del lenguaje no es rápido y no reemplaza de manera inmediata a las acciones, por lo que el pensamiento todavía mantiene su carácter activo. Pero, poco a poco, se va produciendo la internalización de las acciones, mediante los juegos simbólicos, y el niño se va haciendo capaz de remitirse a algo o alguien cuando dicho modelo no está presente.

En este estadio el pensamiento del niño es egocéntrico, emite juicios con referencia a su experiencia personal, sin tener en cuenta lo que los demás niños o los adultos puedan opinar. Otra característica es el razonamiento transductivo o pre-conceptual, que va de premisas particulares a conclusiones particulares (el niño todavía no es capaz de pasar de hallazgos individuales a generalizaciones), no distingue entre los "algunos" y los "todos". Aquí el pensamiento se caracteriza, además, por su irreversibilidad (realizada una acción el niño no logra concebir una sucesión inversa que le permita retornar al punto de origen). 


\section{Pensamiento intuitivo}

Comienza alrededor de los 4 años y predomina hasta los 7 ú 8. La percepción inmediata influye fuertemente en las representaciones mentales del niño, hay una centración visible (el niño prioriza un rasgo o aspecto a la vez, por ejemplo el ancho o la altura). En este estadio, hay una conceptuación creciente y una interiorización de la acción que al niño le permiten progresar en su adaptación a lo real.

Se manifiestan dos tipos de intuición: Simple o primaria y regulada.

La intuición primaria se da en los niños más pequeños y consiste, por ejemplo, en evaluar la cantidad únicamente por el espacio ocupado, esto es, por las cualidades globalizadas de una colección de elementos estudiados, sin analizar sus relaciones.

En el caso de la intuición regulada asistimos a la explicitación de una situación articulada, que aún no constituye una operación, pues continúa regida por las percepciones, pero en una forma mucho más flexible que acerca al niño a la reversibilidad.

\section{Etapa de las operaciones concretas}

Tiene lugar entre los 7 y los 11 años de edad. La acción concreta o inmediata puede reestructurarse en nuevas formas mentales que son reversibles. Esta reversibilidad puede darse tanto por inversión entre los objetos que constituyen las clases, como por diferenciación de las relaciones entre las clases generándose con ello la conservación o la posibilidad de mantener estables o invariables los "nuevos esquemas" o "representaciones", que son lógicas a pesar de las distorsiones perceptivas de lo situacional.

Aparecen representaciones que empiezan a distanciarse de lo subjetivo, favoreciendo la formación de conceptos concretos. El niño logra combinar acciones sucesivas y alcanzar un mismo resultado mediante acciones diferentes.

\section{Etapa de las operaciones formales}

Se presenta a partir de los 11 a 12 años de edad. En esta etapa se da el paso de un pensamiento concreto a un pensamiento hipotético-deductivo en el que la lógica gobierna las proposiciones tanto relativas a problemas experimentales como a enunciados puramente verbales. El pensamiento del adolescente trasciende al plano de las ideas, sin el apoyo de la percepción o de la experiencia, lo que en otras palabras equivale a una subordinación de lo real a lo posible.

\section{El imaginario en los niños}

A la luz de la señalada secuencia del desarrollo intelectual, examinemos la presencia de imaginario infantil. En términos simples, el imaginario es una arquitectura de representaciones que surgen a partir del contacto con la realidad, y con el aporte de la imaginación y la fantasía. Como tal, el imaginario se construye en la memoria de los individuos y responde a la búsqueda de una realidad superior a la del contexto social objetivo. En la medida en que tales representaciones llegan a ser compartidas por otros, pueden ser fundamento de identidades grupales. Suele también entenderse por imaginario a la historia particular construida por los distintos sectores de una sociedad y transmitida por tradición oral de generación en generación.

En los niños, los imaginarios o imago aparecen, como es lógico suponer, a partir de la etapa pre-operacional (2 a 7 años) en que la gradual adquisición del lenguaje y la aparición del juego simbólico favorecen progresivamente el desarrollo de la capacidad de representar lo real. Desde los cuatro años, el 
imaginario del niño puede contener representaciones más complejas que evidencian una conceptuación creciente del mundo que le rodea. Se debe tener en cuenta que el paso a las etapas siguientes en el desarrollo del pensamiento no implica necesariamente la desaparición del imago. Formas arquetípicas de explicar lo real pueden permanecer más allá de la niñez y, de hecho, llegar a constituir parte del bagaje que se deposita en el inconsciente colectivo, en la medida que esas imago puedan estar sostenidas por las estructuras ideológicas de su sociedad.

Las imago constituyen representaciones de la realidad, aunque se elaboran a partir de la realidad no son simples reproducciones de la realidad. Para entender mejor esta distinción, será útil valernos de un par de párrafos escritos por J. L .Borges (1999):

A un chico lo llevan por primera vez al jardín zoológico. Ese chico será cualquiera de nosotros o, inversamente, nosotros hemos sido ese chico y lo hemos olvidado. En ese jardín, en ese terrible jardín, el chico ve animales vivientes que nunca ha visto; ve jaguares, buitres, bisontes $y$, lo que es más extraño, jirafas. Ve por primera vez la desatinada variedad del reino animal, y ese espectáculo que podría alarmarlo u horrorizarlo, le gusta. Le gusta tanto que ir al jardín zoológico es una diversión infantil, o puede parecerlo. ¿Cómo explicar este hecho común y a la vez misterioso?

Podemos, desde luego, negarlo. Podemos pretender que los niños bruscamente llevados al jardín zoológico adolecen, veinte años después, de neurosis, y la verdad es que no hay niño que no haya descubierto el jardín zoológico y que no hay persona mayor que no sea, bien examinada, neurótica. Podemos afirmar que el niño es, por definición, un descubridor y que descubrir el camello no es más extraño que descubrir el espejo, el agua o las escaleras. Podemos afirmar que el niño confía en los padres que lo llevan a ese lugar con animales. Además, el tigre de trapo y el tigre de las figuras de la enciclopedia lo han preparado para ver sin horror al tigre de carne y hueso.

Para el niño, el contacto con la realidad es un proceso más o menos impactante. El niño descubre la realidad y la incorpora en su experiencia de diversas maneras. A partir de esa realidad se genera un universo de representaciones, al que el propio Borges hace referencia:

"Pasemos, ahora, del
jardín zoológico de la
realidad al jardín
zoológico de las
mitologías, al jardín cuya
fauna no es de leones sino
de esfinges y de grifos y
de centauros."

Pasemos, ahora, del jardín zoológico de la realidad al jardín zoológico de las mitologías, al jardín cuya fauna no es de leones sino de esfinges y de grifos y de centauros. La población de este segundo jardín debería exceder a la del primero, ya que un monstruo no es otra cosa que una combinación de elementos de seres reales y que las posibilidades del arte combinatorio lindan con lo infinito. En el centauro se conjugan el caballo y el hombre, en el minotauro el toro y el hombre (...) y así podríamos producir, nos parece, un número indefinido de monstruos, combinaciones de pez, de 
pájaro y de reptil, sin otros límites que el hastío o el asco.

De la infinita posibilidad de representaciones imaginarias, sólo algunas permanecen, son las que pueden obrar sobre el espíritu de las personas. Estas representaciones, que no son efímeras ni casuales, constituyen el imaginario del cual participan quienes comparten, por tradición, una misma cultura.

Los niños elaboran representaciones de la realidad pero ignoran cuanto se refiere a la especificidad del pensamiento, no establecen distinciones entre los cuerpos y el pensamiento. Entre el niño y las cosas la relación siempre será más próxima que la que se da entre el adulto y las cosas. Para el niño las palabras están unidas a las cosas o impactan directamente sobre los cuerpos; por otro lado, los cuerpos exteriores se muestran penetrados de intenciones y de voluntad. En el niño, la realidad exterior parece no ser tan exterior y objetiva como en nosotros. Es por eso que el acto educativo podría no tener la eficacia ni la pertinencia deseada, si es que no tomamos en cuenta que la peculiaridad de la lógica infantil es su realismo como tendencia exclusiva.

\section{Posiciones educativas respecto al imaginario infantil}

No hay uniformidad de criterios en la posición que los educadores adoptan sobre el sentido de su tarea educativa y tampoco lo hay respecto a las implicancias que el imaginario infantil pueda tener en este su quehacer. Es posible reconocer dos tendencias de fondo:

Todas las experiencias del niño están supeditadas a la realidad. Ninguna emoción, ningún impulso, ninguna idea, se suscita a puerta cerrada; en consecuencia, las experiencias del niño se producen siempre en relación con algo o con alguien, a partir de estímulos sociales, afectivos, intelectuales, o estéticos que provienen de su entorno. Bajo esta consideración, se postula que el proceso educativo con infantes preescolares debe orientarse a forjar en ellos una nueva conciencia de la realidad, abriendo nuevas perspectivas dilucidatorias a sus necesidades de comunicación, de conocimiento y de expresión (Dubonoy 2005).

María Montessori, educadora italiana propulsora de los métodos de pedagogía científica aplicados a la educación de la infancia, proponía suprimir de la educación todas las hadas y gnomos porque -según ella- su naturaleza fantástica deforma la mente del niño. Sin llegar necesariamente a este extremo, hay una tendencia a basar la construcción de una nueva conciencia de la realidad en el realismo de los niños, considerando que éstos se limitan a traducir la realidad empleando sus propias palabras (Montessori 2004, 1982). Desde este punto de vista, incluso la fantasía del niño no sería otra cosa que una forma de ajuste a la vida, una vía de expresión supeditada a la realidad antes que una búsqueda por la búsqueda que se pierda en la imaginación.

El niño como el artista evade la realidad. Al decir de Freud, todo niño que juega se comporta como poeta, se crea un mundo real a sí mismo, traspone las cosas del mundo en que vive, establece un orden nuevo completamente a su conveniencia, relaciona juego y fantasía, fantasía y sueño. El niño es un radical, exagera al máximo y en todo, no le atraen ni le impactan los términos medios, desborda los límites que le impone la realidad (Sánchez, D. 1986).

Por naturaleza propia, los niños son imaginativos; desde su fantasía, son capaces de mostrar caminos insospechados que conectan con una realidad diferente, al punto que llegado el 
momento surge una realidad original. En el terreno de lo fantástico el niño se proyecta más allá de lo conocido; elabora representaciones que lo emparentan visiblemente con la creación de mitos y leyendas. De esta manera, avanza en su proceso de estructuración y reestructuración personal, que es una forma de conocerse mejor y de afianzar su sentido de identidad. Por tanto, la tarea de la educación sería ofrecer un ambiente propicio a la actividad, y a la motivación inteligente. En esta perspectiva, el papel más ajustado del maestro vendría a ser el de guía, proveedor de estímulos, materiales y técnicas de trabajo, y observador inteligente, atento y sensible al poder imaginativo y creador del niño.

Los imaginarios o "imagos" como fuente de convicción

Por experiencia propia, creemos en aquello que hemos vivido (si es que nos lo confirman los demás). Como andinos creemos también en aquello que nos dicen nuestros mayores y que podemos comprobar por razonamiento $\mathrm{O}$ experiencia. Junto a las vivencias, la tradición mantiene su peso al abrigo de la mentalidad colectiva que la sustenta y le es afín.

Se ha advertido que las imagos, en su carácter de representaciones colectivas, condensan un inmenso poder, que se sustenta en la tradición, la historia común y las creencias que comparte una colectividad dada (Valdivia 1999: 270). Tales imagos abren un espacio de conexión mental entre determinado acontecimiento y sus causas atribuidas, haciendo que los vínculos personales y colectivos que unen a los integrantes del grupo se exalten y exacerben al punto de anular el azar. Lo azaroso de los hechos es reemplazado de antemano por el poder propiciador que ejercen las imagos.

Así el pensamiento analógico, y sus nexos por semejanza y contigüidad son revestidos de causalidad por intermedio de la creencia. El grupo apela a las imagos para conjurar lo adverso y propiciar acontecimientos favorables. De ahí que las imagos condensen ciertos estereotipos culturales que ayudan a comprender tanto la realidad externa como interna del ser humano (Valdivia, ibid.)

En el mundo andino, los imaginarios contienen personajes míticos cuya fuerza modela el comportamiento y el pensamiento del hombre quechua/aymara. La vigencia de estos personajes se reafirma en las festividades y en las prácticas rituales, contando con los recursos de la imaginería, las canciones, la danza, los relatos de la tradición oral, etc., permitiendo la aplicación de un código preexistente a la explicación, organización y control de un mundo que se manifiesta cambiante.

\section{OBSERVACIONES DE CAMPO}

Este artículo ha sido elaborado a partir de experiencias diversas con grupos de infantes y niños quechuas del sur andino, particularmente en los departamentos de Apurímac, Cuzco y Puno.

Las referencias textuales corresponden a un trabajo de campo realizado en Wayllani (Chumbivilcas-Cuzco) el año 1998. Dicha experiencia tuvo entre sus principales objetivos el de describir el proceso de socialización infantil, en la perspectiva de la propia cultura y de los requerimientos interculturales del contexto. El investigador permaneció durante un mes en la comunidad estudiada, durante ese tiempo hizo observación participante en la comunidad, en hogares y en el Pronoei (Programa No Escolarizado de Educación Inicial), efectuó entrevistas a la promotora, padres de familia y a los niños, las cuales fueron en su mayor parte grabadas. 
El Imaginario Infantil en el Mundo Andino

Las experiencias imaginativas marcan el paso del mundo objetivo y concreto al mundo representativo y simbólico. "Se da aquí un salto dialéctico. El niño desde este momento se instala en el mundo de las imágenes y se pone inmerso en él con todas sus fuerzas y con toda la energía de su capacidad fabuladora" (Hidalgo 1973: 90).

En un primer momento el niño relaciona su pensamiento con el objeto;

\section{"Las experiencias \\ imaginativas marcan el \\ paso del mundo objetivo y \\ concreto al mundo \\ representativo y simbólico"}

si el objeto no es directamente percibido por él, no puede imaginar sus características.

Conversación de una animadora con un niño de tres años

— ¿Tienes uñas en los pies?

$-\mathrm{No}$

- A ver mírate los pies. ¿Hay uñas?

$-S i$

-Cuéntalas

-Once, doce, trece, cuatro.
Un poco más tarde el niño, aunque todavía se circunscribe a describir lo que observa directamente, ya es capaz de imaginar lo que no ve si se le pide que lo haga. La adquisición de la noción de cantidad revela los progresos que logra en su capacidad de representación.

- ¿Cuántas llantas había tenido esta camioneta? (mostrando una lámina)

- Dos

—Dos en un lado, ¿verdad? ¿Y en el otro lado?

-También dos.

-Y en los dos lados, ¿cuántas serán las llantas?

-Cuatro.

Unos años después, el niño logra establecer relaciones y es capaz de pensar sobre situaciones posibles.

Un niño de cinco años en el Pronoei, comentando sobre el profesor de la escuela

El profesor no vino hoy a la escuela, se fracturó el pie. No. Se torció el pie cuando golpeaba la pelota con la mano (cuando estaba jugando vóley). El profesor vive en Santo Tomás, viene aquí manejando bicicleta, deja su bicicleta en la casa de Sallwa, allá arriba. Ahora que vinimos los tres no estaba la bicicleta en el rincón.

A diferencia del mundo occidental urbano, donde el pensamiento del adulto se distancia de las formas de pensamiento infantil. En el mundo andino, va a darse una visible convergencia, una relación solidaria, entre la mentalidad del niño y las concepciones de la sociedad a la que pertenece.

\section{La tradición oral}

En la tradición oral sobresale el cuento, alimentado incesantemente por el mito, 
las leyendas y el testimonio. La narración atrae a los niños por el argumento, la acción, los personajes, las vivencias que se evoca y las emociones que suscitan los acontecimientos.

En el seno del hogar, los infantes tienen oportunidad de escuchar narraciones diversas de sus padres y hermanos. A los niños les agrada escuchar relatos de la tradición y de las anécdotas personales que refieren los miembros de su familia. Este universo forma parte de sus ideas básicas acerca del mundo. Los padres comparten con sus hijos la tradición oral de su comunidad y las madres parecen tener un rol mucho más definido en la transmisión de la tradición oral; en este sentido, podemos hablar no sólo de una lengua materna, sino también de una tradición oral materna que es significativa.

Para los niños de 3 a 5 años es particularmente atractivo el cuento, por tratarse de una narración corta, que desarrolla un motivo evidente, presenta personajes y relata acciones en una secuencia lineal. Este tipo de relato se inscribe, por lo general, en un tiempo pasado y por tanto aleccionador del presente. En los relatos para niños no cuenta el tiempo cronológico: pasado, presente y futuro, sino una relación distinta, un espacio misterioso y primordial: "Hace mucho tiempo...", "En tiempo de los antiguos hombres (Ñawpa Runa)...". Por otra parte, el ambiente extraordinario que incorpora el cuento alienta la imaginación y supera a la realidad, en tanto que hace que todo sea posible y remite muchas veces a un espacio utópico o a una edad dorada.

El niño que concurre al programa no escolarizado de educación inicial puede responder preguntas diversas sobre las cosas y situaciones que observa. Su capacidad de representación se ampara en la información que le procuran sus sentidos y en el poder de la memoria.
_ ¿Con qué cerramos la puerta?

- La cerramos con llave.

— ¿Qué hace el niño con la llama?

- La está jalando.

- ¿Para qué la jala?

- Para que vaya al pueblo.

- ¿Con qué está amarrada la carga?

- Con una soga.

- ¿Para qué amarramos con una soga?

- Para que no se caiga.

- ¿Camina el chico con los pies

descalzos?

-Con ojotas.

_ ¿Para qué se pone ojotas?

- Para que no le entren espinos.

- ¿Alguna vez te ha entrado un espino?

-Sí.

- ¿Te ha hecho llorar?

-(No responde)

—(Otros niños: Ja, ja, ja, jaaaaa.... le habia hecho llorar....)

Entre los tres y cinco años, sin embargo, el infante no parece estar aún en condiciones de retransmitir la tradición, apenas le es posible hilar oraciones aisladas. A partir de los seis años su habilidad narrativa se acrecienta y se muestra capaz de relatar hechos concretos que de alguna manera le son familiares, como los relatos de 'la gallina', 'la oveja' y 'el hombre que se volvió loco'. Algunos ejemplos servirán para apreciar mejor los progresos de niños preescolares en la verbalización del pensamiento:

- Comemos chuño en sancochado y en mazamorra.

- Cocinamos en una olla, prendemos el fogón con fósforo, hacemos fuego con bosta.

- Podemos hilar esta lana para hacer bayeta. 
- Me gusta jugar. Juego con latas, con una botella y una pelota. No tengo muñeca, la he perdido.

- Mi papá ha ido a vender papa. De la papa hacemos chuño. Cuando hay helada, extendemos la papa en la pampa.

- Estaba una paloma en su nido y la maté, alli había un huevo. Me llevé el huevo. Un día mi hermano agarró una paloma con la mano. Estamos criando un kullku en una jaula, le he hecho cortar sus alas con una tijera.

"En distritos y

comunidades campesinas

diversas, los niños están

familiarizados con

canciones agrícolas y/o

ganaderas que permiten

ejemplificar la singular

belleza y expresividad de

estas manifestaciones."

Otros relatos revelan aspectos de la socialización normativa que se le inculca, y la repetición de algunas versiones míticas que se irá acentuando a la medida de su maduración intelectual, como ocurre en los relatos de 'Nuestro Señor' y 'El zorro que se cayó del cielo'.

En el mundo andino los niños captan y reproducen el carácter dialogal y eminentemente comunicativo de las manifestaciones poéticas, fundamentalmente a través del canto ritual, propiciatorio, festivo y amatorio que practican los adultos. Los niños de corta edad son receptivos a la expresión poética.
Eljuego de roles

El juego es, en cierto modo, una proyección cultural del rito y comulga con el discurso mítico como fuente explicativa de la realidad. A los niños les gusta dar vida a los personajes, verbalizar de modo coloquial la acción, interpretar los gestos. Por eso les son tan preciados los juegos de roles, donde es común que los diálogos se acompañen con gestos teatrales y expresiones onomatopéyicas. A partir de los tres años de edad surge en la vivencia cotidiana del niño andino el juego de representación o juego dramático que apela a materiales sociales. El argumento de la representación es hilado espontáneamente y simula rasgos del mundo familiar y social.

Los juegos de representación se complementan con los juegos de lenguaje. Estos juegos oscilan desde el nivel más primitivo de juego verbal, que es el proceso de formar sonidos mediante la articulación o la fonación (balbuceo, vocalizaciones repetitivas y rítmicas, canturreo) hasta el denominado juego social (rimas, refranes, proverbios, cantos, adivinanzas y juego con conversación).

En los juegos de niños mayores, hemos visto que los infantes también intervienen como aprendices, conforme a sus limitadas experiencias. Los niños en edad escolar, en cambio, ya muestran mejor conocimiento de las situaciones interculturales, como lo es la compra en una tienda del distrito (el vendedor habla más castellano y el comprador necesita también participar de algunos códigos para la transacción).

En el mundo rural quechua, los juegos estrictamente verbales son escasos, quizás el de las adivinanzas o watuchikuna sea el más ampliamente difundido, a los niños les divierte mucho formularlas y contestarlas. Conviene tener presente que watuchi (adivinanza) se asocia al campo 
semántico de 'recordar', pero también de 'amarrar', de 'indagar' como en watuy (adivinación en coca que hacen los chamanes chumbivilcanos), de hacer asociaciones imaginativas, por ejemplo en los sueños. Se trata entonces de un juego con alto componente intelectual.

Infantes de educación inicial demuestran conocer un repertorio importante de adivinanzas quechuas. El watuchi, chiqt'awinaka o adivinanza es muy común en las sociedades rurales andinas, refleja la cultura, los intereses y el medio ambiente natural. La adivinanza se cuenta generalmente por las noches al calor del fuego hogareño. Los objetivos de la adivinanza en los pueblos andinos son principalmente la distracción y la prueba de la capacidad de discernimiento.

La representación o literatura dramática infantil es seguramente la menos documentada en su aspecto oral. Los registros testimoniales son una fuente imprescindible para un acercamiento a esta fuente de expresión de las imago.

\section{Las canciones}

Un niño(a) de tres años puede dominar ya muchas canciones en su lengua materna (quechua/ aymara), las aprende de su madre. Las situaciones de juego en el campo van matizadas de cantos y danzas. Las metáforas, metonimias y otras representaciones simbólicas se unen con el ritmo, la coreografía y el sentido festivo de la cultura, en la danza y la canción. El género lírico, se expresa a través de la poesía y las canciones, que cautivan al niño por la rima y el ritmo, expresión de la belleza. La rima, el ritmo, las imágenes sonoras de gran intensidad, unidas al movimiento y gracia corales, cautivan a los pequeños. La multiplicación y la repetición, figuras comunes al canto andino, tienen un poder de fijación o adherencia que son tan solicitados en el desarrollo de la comunicación y en el aprendizaje infantil en general. Tomemos como ejemplo: Espejito, espejito, espejito del jardín/ Díme cómo soy yo y no me engañes (Canción quechua); Ser viejo es difícil/ ser vieja es difícil/ pero el joven es agilito q'ax, q'ax, q'ax / awkiñasa ch'amawa, taykañasa ch'amawa, waynitu q'ax, q'ax, q'ax (Canción aymara). Las canciones amorosas, bucólicas y satíricas son parte de la vida cotidiana y festiva de los pueblos andinos. La danza es, por otra parte, un lenguaje apropiado para expresar íntimos sentimientos y sensaciones.

Son abundantes las canciones tradicionales que acompañan a las prácticas productivas. En distritos y comunidades campesinas diversas, los niños están familiarizados con canciones agrícolas y/o ganaderas que permiten ejemplificar la singular belleza y expresividad de estas manifestaciones. Un aspecto interesante del canto en las actividades agrícolas es el contrapunto entre varones y mujeres. Tal se aprecia, por ejemplo, en P'asña Aysay (El rapto de la joven), Carnaval de Tinta, Enciende el fósforo (K'axilu). El grupo de varones canta unos versos y el grupo de mujeres responde otros, y así sucesivamente mientras adelanta el trabajo.

Mediante las canciones, cada pueblo retrata la realidad, poniendo en relieve su imaginario colectivo. Los niños refuerzan su propio imaginario asimilando estos referentes sociales, que aluden a los dioses/montaña, el encanto de las lagunas, las aguas del amor o del olvido, las plantas confidentes y los recodos testigos del diario vivir, el poder premonitorio de la coca, o los presagios que encierra el canto de las aves (Sánchez R. 2015). Las canciones ofrecen asimismo modelos de conducta y refrendan el carácter legendario de los personajes que pueblan el imaginario popular: el chofer arriesgado, el osado 
abigeo, el soltero empedernido, el eterno enamorado, la mujer inolvidable, el santo patrón del pueblo, la cruz milagrosa. Otras veces, las canciones aleccionan y previenen sobre los tropiezos y azares de la vida: paloma ingrata, mujer traicionera, cárcel de piedra, fatal destino. Este universo se irá haciendo familiar al niño al paso de los años, pero él va a gustar preferentemente de las canciones picarescas y las letras festivas y heroicas.

En Wayllani, comunidad de la provincia de Chumbivilcas - Cuzco, escuchamos la Canción del Zorrino, cuyas letras dicen:

\section{"Suéltame nomás hermanita Suéltame nomás hermanito Ahorita voy a decir chhall (onomatopeya de algo que se quiebra) Ahorita voy a decir chhall."}

Esta canción interpretada jocosamente por un niño de cinco años, motivó las risas de sus compañeritos en el centro no escolarizado de educación inicial. Pudimos advertir que los niños de cuatro y cinco años ya están familiarizados con el uso de metáforas, así, en este caso, el vocablo onomatopéyico sustituye el olor característico que despiden los zorrinos y que los niños asocian con la ventosidad de los humanos.

El toro y el caballo, asimilados al ecosistema chumbivilcano, por ejemplo, son reinterpretados y la cultura popular les asigna un carácter mítico. Las jornadas frente al toro son parte de una epopeya viril que perenniza el canto:

\footnotetext{
"En la plaza de Colquemarca en la plaza de Colquemarca hay un toro negro, un toro bravo con roja enjalma.

Dice que he entrado en mi caballo a mi caballo lo ha corneado. Asíse quedará mi caballo después de salvarme la vida."
}

Como dice la canción "es grande el poder del toro", pero no menos grande es el temple del hombre que ante él arriesga su vida. Toro y caballo son arquetipos de una manera de entender el mundo y el sentido de la vida.

\section{Los personajes}

Los personajes actúan en universos extraordinarios, de mano con los recursos del pensamiento mágico. Ora habitan la tierra, ora pueden acceder a las regiones celestes o confinarse en el inframundo, utilizando el poder de un intermediario o de un objeto encantado. El zorro asiste a un banquete en el cielo, llevado en alas de un cóndor; una muchacha encuentra a un picaflor que la convierte en ave; el guerrero Chuntawachu se convierte en árbol, echa profundas raíces en la tierra y vence a la sierpe Yakumama; el colibrí traspone la puerta del arco iris y obtiene el agua para los hombres; una gaviota del lago le regala dos de sus plumas a un pescador, éstas se convierten en una barca y unas redes nuevas; una mujer entra al puquio y no regresa jamás; una hermosa doncella se convierte en estrella. Podríamos seguir indefinidamente con los ejemplos.

En la cultura andina el imaginario infantil tiene a los animales como personajes favoritos, en lo que se conoce como aranway en quechua y sallqa en aymara. Las variantes del zorro, la wallata, la perdiz, el cóndor, el hak'akllo, el puma, el cuy, entre otros, así lo testimonian. La incorporación de nuevos personajes como el burro, la oveja, la vaca, etc., demuestran la sensibilidad del género al contexto intercultural que envuelve al mundo andino. Entre los aymara, los parlanaka o arsunaka que tratan de la fauna silvestre adoptan el nombre de sallqa, variante narrativa cuya tradición era propia de las actividades del hilado, tejido y deshoje. 
En el relato fantástico, la actuación de los personajes pone la magia al alcance del niño y lo orienta de una manera particular en el mundo. La percepción mágica resulta una facultad que permite explicar la realidad mediante el sentido atribuido a algunos signos o señales, que ordinariamente serían sólo figuras metafóricas. A través de elementos mágicos el niño alcanza respuestas accesibles a sus grandes interrogantes acerca de cómo es el universo y cómo debe conducirse en él.

El imaginario nutre al niño con modelos sociales refrendados por la literatura oral tradicional. El gentil o ser de una antigua humanidad, los mukis de las minas, los duendes que habitan los higuerones, las sirenas de los ríos, forman parte de la realidad cultural en que están inmersos los niños andinos.

\section{El Soqa o Momia (Relato del niño Percy Rendón, Wayllani)}

Un borracho se había quedado dormido. Entonces el soqa se presentó a la mujer con la apariencia del marido y se acostó con la mujer. Cuando el verdadero marido llegó y encendió el mechero, encontró huesos amontonados y a la mujer muerta.

Las achike (adivinas andinas) son distintas a las brujas que presentan los relatos europeos. Los incestuosos ambulan por lugares solitarios convertidos en qarqachas, o penan en las regiones nevadas de las altas montañas. Todos estos seres fantásticos, que se congregan en el imaginario, son necesarios porque a través de ellos se concretan una serie de contenidos y presencias anímicas con rostro y personalidad asequibles. El niño apela a estas figuras para explicarse el mundo de conformidad con su visión realista, teñida de animismo y artificialismo. Héroes y antihéroes dibujan el amplio espectro de los comportamientos que serán objeto de control social.

\section{El imaginario sobre los padres y parientes}

Muchos niños de 3 a 5 años tienen dificultades para enunciar el nombre de sus padres. En general acostumbran dirigirse a ellos como papay (papá), mamay (mamá), antes que por sus nombres propios. Igual pasa con los abuelos: ¿Hamuranchu awluyki? (¿Vino tu abuelo?), salvo que tenga que distinguir entre dos abuelos, por ejemplo entre el abuelo materno y el abuelo paterno, pero en el caso de otros parientes y de los hermanos acostumbra reconocerlos por sus nombres, así por ejemplo: Phaway waqharamuy tiyuyki Suiluta (Corre a llamar a tu tío Zoilo), Sullk'ay Heracliuchawan kashaqtiy zorrowan ovejata qechuchikuyku (Estando con Heraclio, mi hermano menor, nos hicimos quitar la oveja con el zorro).

Algunos niños identifican primero el apellido y luego el nombre de sus padres. Quizá porque en la comunidad identifican a las personas por el grupo familiar, generalmente el apellido paterno del padre de familia: los Benitos, los Suárez, etc. A medida que la modernidad alcanza a los poblados rurales, se producen cambios lingüísticos. El vocablo papay (mi papá) que procede del castellano ha prácticamente reemplazado a taytay $(\mathrm{mi}$ padre) que se reconoce en el habla de los adultos. Lo mismo viene ocurriendo con otros términos relativos al parentesco, tales como como abuelo o awluy en lugar de machulay (mi abuelo, mi viejo), abuela o awlay, hermanuchay (hermanito) por wayqichay, hermanachay (hermanita) por panachay (hermana del varón) y ñañachay (hermana de la mujer).

El niño siente a la madre como su protectora, especialmente durante sus primeros dos años de vida. De hecho, él percibe claramente que ella le ayuda a satisfacer sus necesidades biológicas, le asea, le da cariño y especial atención cuando se enferma. 
Un erqe, niño de algo más de 3 años, habla de su verruga

- A mi me ha salido una verruga aquí (mostrando una de sus manos).

- ¿Y en tu otra manito?

-En esta no.

- ¿Con qué podríamos curar esta verrugita?

-Con sal.

-Con sal. Pero, tu mamá ha debido curarte.

- Sí me ha curado. Aquí tenía una verruga que ya sanó, ya desapareció.

"De alli que un mejor entendimiento de estas imago puede acercar más a educadores y niños, en pos de ayudar mejorar las interacciones infantiles en todos los espacios de socialización."

Los niños saben el quehacer diario de sus padres, identifican sus roles, saben donde están y por qué razones se ausentan de la casa, por ejemplo si fueron a comprar algo o a realizar una gestión, como podría ser el arreglar una queja ante la autoridad. En la visión infantil sobre el padre, destaca su rol de manutención y protección. Para el niño su padre es poderoso y por ello suele describirlo como < grande $>$.

Un niño de tres años habla de sus papás -Augusto ¿quién es tu papá?
-Mi papá.

- ¿Cómo se llama tu mamá?

-Mi mamá.

—QQué está haciendo tu papá ahora?

- Está en mi casa. En la faena.

-Y tu mamá?

— ¿Mi mamá? A dónde habrá salido.

Un niño de tres años dice que su papá es grande

- ¿Tienes papá?

-Claro que sí.

- ¿Cómo se llama tu papá?

-Es grande... No tiene nombre.

Desde pequeño el niño toma conciencia de la fuerza física y el carácter de su padre, por eso confía en él ante situaciones de incertidumbre o de peligro para su integridad física, la de los miembros de su familia o ante cualquier amenaza de menoscabo al patrimonio familiar.

Los hijos, en general, piensan que los papás hacen lo correcto, que son buenos. Aprecian si sus padres son bondadosos y pueden calificarlos de severos, si acostumbran pegar. Advierten sí que el papá es quien se enoja más en la casa cuando alguno de los hijos comete una falta. La niña teme la ira del padre y procura no provocarlo, las principales quejas se condensan en la siguiente denuncia: "Mi padre es muy abusivo, de todo agarra, palo y piedra". Los hijos menores se saben más vulnerables, según ellos los mayores reciben menos castigo.

Un pequeño es capaz de identificar a sus hermanos mayores y menores, conoce sus nombres. Conoce también de cualquier otra persona que pudiera estar vinculada por alguna obligación a su familia, por ejemplo un pastor que esté a cargo del rebaño, aunque no puedan referir su nombre. 
El imaginario sobre los animales

Los niños aprecian a sus animales domésticos, algunos pueden enunciar sus nombres, sobre todo de sus perros. Saben con qué se alimentan. Emiten los sonidos característicos de cada animal. Saben cuál es la utilidad o servicio que los animales prestan en la casa. He aquí algunos testimonios de niños de tres y cuatro años en una comunidad andina, que permiten apreciar la valoración funcional de los animales:

- Ayer he jugado, también he cuidado mi vaca. Tenemos una sola vaca y no nos alcanza. Ordeñamos un poco de leche, la vaca tiene una cría que ya está grande. También tenemos unas cuantas ovejas.

-Tengo un gallito pequeño. El gallo indica la hora, canta en la oscuridad.

-Tengo un perrito, me muerde a veces.

- El gato agarra a los ratones, eso nomás hace. Los ratones se comen el maiz, la carne, las habas, toda la despensa.

Los niños pequeños están al tanto de lo que sucede con sus animales, saben si son machos o hembras, si hubo alguna cría. Pueden informar si alguna de las crías del perro ya abrió los ojos. Pueden decir si la perra tuvo una o varias crías, algunos todavía no pueden indicar la cantidad de crías si éstas son más de tres o cuatro. También identifican las fuentes de peligro para las personas y para sus animales. Por ejemplo, saben que la gente muere atropellada en la carretera, que el zorro se come o puede comerse a las ovejas. En el imaginario del niño están las características distintivas de los animales, tales como la valentía del perro, la astucia del zorro o la fuerza del oso.
La representación de las cosas

Respecto a las cosas, poseen nociones de tamaño, de color (aunque todavía confunden los colores), de forma, de ubicación en el espacio. Pueden identificar las partes principales de las cosas u objetos. Expresan nociones de distancia, si un lugar está cerca o lejos. Cuando dibujan un carro pueden decir que viaja a un pueblo cercano o una ciudad distante. A la vista de una imagen o ilustración se muestran entusiastas y describen con habilidad lo que observan, haciendo comentarios sobre detalles posibles.

Atribuyen espíritu y voluntad a las cosas. Piensan que las cosas se comportan como los hombres, pueden cansarse, por ejemplo un camión que lleva mucha carga puede ya no querer andar.

Otro poder fascinante para los niños se contiene en la palabra. Las palabras, en el imaginario infantil, transforman las cosas, trasladan a otros tiempos y otros espacios, desatan las fuerzas de la naturaleza, pero también asustan al granizo, apaciguan las tempestades, hacen crecer a las plantas, animan a las cosas. Del dios Wiraqocha se decía, por ejemplo, que "con su sola palabra hizo nacer el maíz y las legumbres".

El sueño y los imaginarios

Los pequeños relatan algún sueño que les haya impresionado: un accidente, una pelea entre animales. Para muchos niños el dormir y el sueño son excluyentes, el que se queda dormido no sueña, la memoria está ligada a la vigilia. En quechua el sueño o mosqhoy o samka en aymara se vincula con la vista, en mis sueños he visto esto o lo otro, dicen los niños. Los niños no explican el sueño como producto del pensamiento, cuando 
sueñan haber hablado con alguien o escuchado una melodía piensan que percibieron con el oído.

(El sueño de un niño de cuatro años)

En un nidito había un gorrioncito, pero ese gorrioncito se murió, entonces resucitó. Una oveja se perdió entonces fui yo, a modo de buscarla, entonces un cóndor la apresó y un hombre llegó al sitio, eso es todo.

\section{(Otro sueño)}

En mis sueños me hablaba una voz, quién sería. Me llamaba por mi nombre. Lo escuché clarito en mi oído.

Los sueños y el acto de dormir son percibidos por el niño, pero también por el adulto, como provenientes del exterior. Por eso dicen, cuando ya están por dormirse: En quechua puñuy aysawashan (el sueño me está jalando), y en aymara ikiwa puritu (ya me está llegando el sueño).

\section{CONCLUSIÓN}

En el mundo andino, las imago infantiles se interconectan con la tradición oral, el juego, la danza y la canción. En este sentido, el imaginario infantil está constituido por representaciones originales del propio niño, pero también por creencias colectivas que éste asume como producto de su socialización, las cuales guardan coherencia con la lógica de su mentalidad infantil. Este es, seguramente, uno de los principales puntos de ruptura o desencuentro, cuando hacia los seis o siete años de edad el niño transita del hogar a la escuela.

En niños de comunidades quechuas del surandino peruano el poder de las imagos se sustenta en la tradición, la historia común y las creencias que comparte la colectividad, de manera que los nexos por semejanza y contigüidad, propios del pensamiento analógico, son revestidos de causalidad por intermedio de la creencia. De allí que un mejor entendimiento de estas imago puede acercar más a educadores y niños, en pos de ayudar mejorar las interacciones infantiles en todos los espacios de socialización.

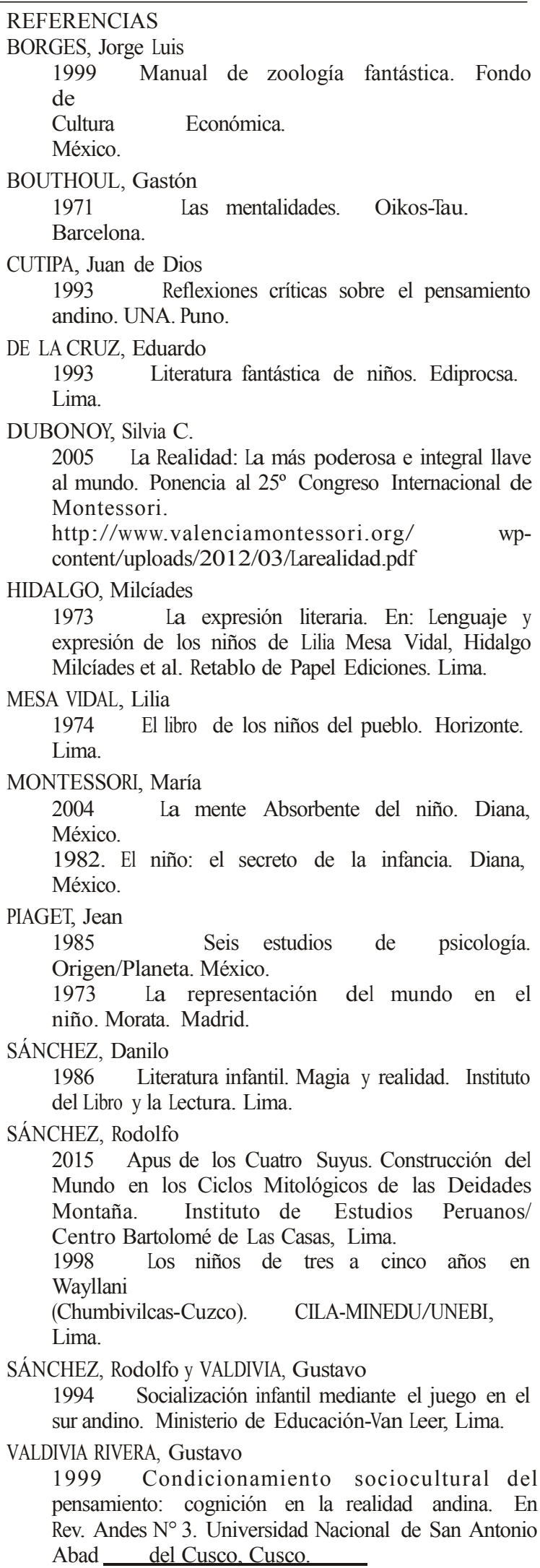
expresión de los niños de Lilia Mesa Vidal, Hidalgo Milcíades et al. Retablo de Papel Ediciones. Lima. 